\title{
M igrações humanitárias ou migrações econômicas na fronteira Brasil/Colômbia: reflexões sobre deslocados e conflitos
}

Gabriel Angel Jimenez Lopez ${ }^{1}$

\section{Resumo}

Este artigo resulta de um trabalho de dois anos de pesquisa bibliográfica e de campo. 0 intuito, aqui, é analisar os dados coletados e acrescentar novos elementos de análise, cujo objetivo é aprofundar alguns aspectos da migração forçada, a partir da experiência e trajetos dos refugiados. Trata-se, então, neste texto de examinar, desde uma perspectiva antropológica a condição do sujeito refugiado, com base em minha pesquisa de campo com solicitantes de refúgio e refugiados colombianos nas regiões de Tabatinga, Manaus e São Paulo. Concomitantemente, procuro por meio das narrativas nativas, explorar as causas que produzem o deslocamento forçado, bem como o papel dos organismos humanitários que trabalham na recepção, gerenciamento e integração dos refugiados.

Palavras-Chave: Colômbia; conflito; refúgio; deslocamentos; violência

${ }^{1}$ Pesquisador do Laboratório de Estudos migratórios. Graduado em Ciências Sociais, UFSCar. Contato: socrates980@gmail.com 


\section{Humanitarian migration or economic migration in the Brazil/ Colombia border: ref lections about displaced people and armed conflict}

\section{Abstract}

This article is the result of a two years' research on scientific literature and fieldwork. The purpose here is to analyze the collected data and add new elements of analysis, which aims to deepen some aspects of forced migration, taking into account the experience of refugees. I examine from an anthropological perspective the refugee condition, based on my fieldwork research with asylum seekers and Colombian refugees in the regions of Tabatinga, Manaus and São Paulo. I also look through the native narratives to explore the causes of forced displacement, as well as the role of humanitarian agencies working in the reception, management and integration of refugees.

KeyWords: Colombia; conflict; refuge; displacement; violence.

\section{Introdução}

Dado a intensificação dos conflitos internos, religiosos, étnicos ou "intervenção humanitária" ${ }^{2}$ que tem ocasionado o desloca-

${ }^{2}$ Vale destacar, que o termo "intervenção humanitária" foi utilizado pela primeira vez pelo Conselho de Segurança da ONU na Somália. Na Resolução 794 de 1992, o Conselho de Segurança utilizou o Capítulo VII para autorizar os Estados-membros "to use all necessary means to establish... a secure environment for humanitarian relief operations". Em seguida, o Conselho de Segurança autorizou as seguintes intervenções humanitárias: Bósnia e Herzegóvina (1992-5), Ruanda (1994), Haiti (1994),

Albânia (1997), Serra Leoa (1997-2000) e Timor Leste (1999). No entanto a eficácia desse conceito permitiu que posteriormente fosse também utilizado eufemisticamente na "intervenção" militar no Iraque 2003, Líbia 2011 e, mais recentemente, tem sido 
mento em massa de milhões de pessoas ${ }^{3}$, pretendo neste texto, examinar, desde uma perspectiva antropológica a condição do sujeito refugiado, a partir de meu trabalho de campo, realizado com solicitantes de refúgio ${ }^{4}$ e refugiados colombianos nas regiões de Tabatinga, Manaus e São Paulo. Concomitantemente, procuro por meio das narrativas nativas, explorar as causas que produzem o fenômeno migratório, bem como apontar alguns aspectos dos organismos humanitários que trabalham na recepção, gerenciamento e integração dos refugiados.

Migração induzidas ou forçadas por situação de guerra e conflito são fenômenos antigos na história da humanidade. Contudo, vale destacar, que esse processo migratório se tem intensificando na sociedade contemporânea na medida em que se desenvolvem os conflitos e as ações bélicas. Para pensar esse fenômeno migratório, bem como a questão dos refugiados, quero propor aqui discutir essa questão a partir do conceito de condição de sujeito refugiado, noção que elaboro, com base em minha pesquisa de campo, na qual reflito sobre os processos de subjetivação do sujeito em situação de refúgio. Trata-se, nesta primeira parte do texto, de uma tentativa de explorar como o sujeito em situação de refúgio, durante o processo de diáspora, passa a se tornar social e politicamente em um sujeito não-cidadão. Veremos ao final, como as dicotomias sujeito/

evocado por algumas potencias ocidentais ante o conselho de segurança da ONU, como tentativa em uma possível "intervenção" militar (externa) na Síria. (O debate conceitual sobre intervenção humanitária. PUC- RIO- Certificação Digital №0510714/CA). http:// www.maxwell.lambda.ele.puc-rio.br/10564/10564_4.PDF

${ }^{3}$ De acordo com ACNUR (2013) a final de 2012 havia mais de 45 milhões de pessoas deslocadas forçadamente de seus países de origem. Vale dizer, no entanto, que essas estimativas numéricas evidenciam a magnitude desse fenômeno, e como o deslocamento forçado tem ganhado força desde os inícios deste milênio.

${ }^{4}$ Vale destacar, que embora o sujeito solicitante de refúgio, já em si por sua própria condição é um refugiado, muitos deles não conseguem serem reconhecidos como refugiados, permanecendo, assim, em uma situação de não documentação como pude constatar durante o trabalho de campo em Manaus. 
cidadão, e sujeito/não-cidadão, se fazem presentes na condição do sujeito refugiado.

Quero acrescentar, ademais, que o termo cidadão, assim como o termo direito foram também categorias nativas que ouvi recorrentemente durante o trabalho de campo. Portanto, são termos dos quais pretendo brevemente tratar, até porque são conceitos que atravessam as fronteiras disciplinares. Tais conceitos, de início tomados de uma noção nativa, projetam-se, em certa medida, nas relações entre refugiados e comunidades locais, como tentarei explicar mais adiante.

Apesar, da migração forçada ter tomado importante notoriedade no contexto político internacional, estudos acadêmicos têm contribuído para discutir esta questão, desde distintas áreas multidisciplinares. Contudo, no Brasil, os estudos que abordam a temática do refúgio são ainda incipientes (BAENINGER, 2008a). Quando realizados aparecem principalmente como parte das áreas das relações internacionais, da ciência política, do direito e da sociologia, com destaque para os trabalhos de Moreira (2006), Andrade (1996; 1997), Baeninger (2008), Perin (2011), Milesi (2003), Araújo e Almeida (2001) e Liliana Lyra Jubilut (2003).

O intuito, aqui, é acrescentar um pouco a essa bibliografia e abordar tal processo migratório, desde uma perspectiva antropológica, de modo a contribuir um pouco na discussão sobre o êxodo forçado, dinâmicas de guerra e dispositivo humanitário, baseando-me (principalmente) nas narrativas e experiências dos sujeitos refugiados que fizeram parte da pesquisa. Trata-se, portanto, de ressaltar neste texto, essas histórias, e verificar o que essas narrativas dizem sobre sua condição de refugiados, bem como o que elas nos dizem sobre as causas de sua diáspora forçada.

O texto está estruturado em duas partes, cuja relação e articulação são apenas uma tentativa de apontar análises, ainda que 
preliminares, sobre a tríade migração forçada, dinâmicas de guerra $^{5}$ e "dispositivo humanitário" (este último conceito é tomado de empréstimo [AGIER; 2003; 2008] que, para os fins deste trabalho, tentarei explorar um pouco mais). Na primeira parte discuto a migração forçada, para a qual exploro a condição do sujeito refugiado, tomando como categoria de análise o conceito de cidadania, para argumentar como o sujeito em situação de diáspora, na sociedade contemporânea, passa a se tornar social e politicamente em um sujeito não-cidadão.

Na segunda parte, analiso a relação migração forçada e dinâmicas de guerra, pensada neste texto como processos imbricados e, ao mesmo tempo, sendo apresentados como processos que se tornaram "necessários" para a acumulação de capitais. Para fundamentar esse argumento, tomou como recorte de análise o conflito na Colômbia, como espaço especifico dessas dinâmicas, e uma possível extrapolação desse recorte, na medida em que parto dele, para pensar a relação migração forçada e dinâmicas de guerra em contextos e cenários mais abrangente.

\section{A "emergência" de um "novo" sujeito}

Retomando o primeiro eixo de análise que proponho neste texto, quero começar retratando que, desde meados do século $\mathrm{XX}$, o fenômeno da migração forçada passou a se constituir no cenário internacional em um dos eventos contemporâneos de maior repercussão global, em razão das dimensões políticas, culturais, jurídicas, econômicas e sociais que este produz. Existe de fato, uma grande quantidade de literatura focada sobre esse tema. Hobsbawm (1995), por exemplo, em seu celebre livro A era dos extremos, descreve como as duas conflagrações mundiais e o ex-

\footnotetext{
${ }^{5}$ Utilizo aqui o conceito de dinâmicas de guerra, com o intuito de apontar não tanto sua evolução em técnicas de combate, meios tecnológicos, mecanismos disciplinadores, senão como um processo que se torna necessário para a acumulação de capitais.
} 
termínio contínuo de populações e grupos étnicos levaram ao deslocamento em massa de mais de 40 milhões de pessoas, ao termino da segunda guerra mundial.

Desde outra perspectiva, Hanna Arendt (1989), por outro lado, chama a atenção para como depois da primeira guerra mundial a desnacionalização de alguns grupos e o surgimento de minorias nacionais aumentaram o número de apátridas e refugiados no cenário internacional. Fato que por sua vez levou, concomitantemente, à constituição de um "novo" sujeito, a saber: um sujeito sem nacionalidade que não pertencia a nenhum Estado nacional.

Apoiado nessa perspectiva, veremos, a seguir, que a "emergência" desse novo sujeito, do sujeito em situação de refúgio ${ }^{6}$ (que analiso enquanto grupo especifico) na sociedade contemporânea, passa a se constituir, social e politicamente, em um sujeito não-cidadão. Baseado nesse argumento, veremos ao final do texto, o papel central dos Estados-Nação na produção e reprodução desse sujeito sem Estado. Como exemplo de análise recorrerei às experiências dos refugiados no Brasil (ou pelo menos me refiro àqueles com os quais dialoguei durante o trabalho de campo) que, por meio de suas narrativas, apontavam sobre certo descompasso entre serem reconhecidos como refugiados, e de outro, gozar de um estatuto de cidadãos. Indicando, a dicotomia entre um indivíduo cidadão, e um indivíduo não-cidadão.

Vale salientar, que essas noções, derivadas inicialmente das experiências nativas, são um ponto importante de reflexão na análise sobre a relação entre território, Estado-nação e cidadania, bem como, através delas, também podemos refletir sobre os processos geopolíticos e biopolíticos, que se desenvolvem em escala

\footnotetext{
${ }^{6}$ Embora os estatutos de não-cidadão se remetam a diversos grupos sociais (apátridas, migrantes etc.) meu recorte de campo trata especificamente sobre os refugiados e, neste sentido, viso discutir a questão dos refugiados enquanto grupo especifico de pesquisa.
} 
global, cujos processos econômicos, políticos, sociais e militares não cessam de produzir indivíduos não-cidadãos (BIRMAN, 2009). Simultaneamente, essas noções nativas, comparadas a um ponto de vista político e estatístico, permitem constatar que a existência desse sujeito sem Estado (ou não reconhecido por nenhum deles) na evolução contemporânea se intensifica (principalmente) sobre as "margens do mundo", na medida em que se desenvolvem os conflitos e as ações bélicas, como bem o demonstra o trabalho de Agier (2003) ao analisar as populações deslocadas que vivem nos campos de refugiados.

Tomando como referência os campos de refugiados, Agier mostra como esses "nichos" passam a se constituir em centros de retenção às "margens dos Estados", empregando aqui o termo de Das e Poole (2008) ${ }^{7}$ para apontar como esses locais se situam e se tornam em espaços extrageográficos de controle e confinamento em territórios, que ao se tratar os deslocados como vítimas, não reconhece a esses o estatuto de cidadão (BIRMAN, 2009). Gostaria de acrescentar a essa questão que nesses espaços extraterritoriais, ou também denominados pelo dispositivo ${ }^{8}$ (do) humanitário de corredores humanitários ${ }^{9}$, também se mol-

\footnotetext{
${ }^{7}$ Veena Das e Deborah Poole (2008) elaboraram essa noção destacando a ideia que o "estado", longe de estar ausente das margens ou periferias, tem um papel fundamental na configuração e no controle destas regiões.

${ }^{8} \mathrm{O}$ dispositivo (do) humanitário, ademais de aplicar modelos disciplinadores, também utiliza uma linguagem confusa, que se exprime no discurso (do humanitário enquanto pratica discursiva).

${ }^{9}$ Sobre esse conceito, de acordo com Macedo (2006), as Nações Unidas, preocupadas com os meios para facilitar as operações de assistência humanitária, decidem criar, através da resolução no 45/100, os corredores humanitários, em seu artigo 6 estipula: “a título temporário, lá [no local afetado] ou onde for necessário, e de modo concertado entre os governos envolvidos e os governos e organizações intergovernamentais, governamentais e não-governamentais interessadas, corredores de urgência para a distribuição da ajuda medicinal e alimentar de urgência". 0 autor, ademais, destaca três tipos de corredores humanitários: os de simples acesso, que favorecem a chegada do socorro às vítimas; os de evacuação, que permitem a fuga das pessoas em perigo iminente, e os de retorno que possibilitam o regresso dos refugiados (MACEDO, 2006, p. 22).
} 
dam as práticas políticas de controle, regulação e disciplinamento que constituem aquilo que denominamos de Estado.

Esses espaços se situam em zonas contíguas de fronteiras, espaços territoriais geopoliticamente definidos, nos quais os processos biopolíticos de controle e disciplinamento também são onipresentes. Essas formas disciplinares de poder, como descreveu Foucault (1999), projetam na distribuição espacial dos indivíduos uma técnica de poder que implica uma vigilância constante e supõe um registro contínuo (MENEGHEl, 2008). A forma como se exprime essa política está representada no controle diário daqueles que são confinados nesses espaços (os denominados corredores humanitários, nos quais se estabelecem os campos de refugiados, ou também chamados de centros de acolhida (CA), cuja função consiste na recepção, atendimento e gerenciamento daqueles que fogem da ofensiva guerreira).$^{10}$ Espaços de controle da circulação das pessoas, dos alimentos, materiais e medicinas etc.

Em outras palavras, trata-se de espaços gerenciados pelo "governo do humanitário" (AGIER; 2008) que envolve tanto "os senhores da guerra e do mundo", quanto os organismos internacionais (entidades supranacionais, intergovernamentais, governamentais, ONGS e entidades de caridade) que operam em escala planetária (BIRMAN, 2009). Trata-se, portanto, de um poder baseado na vigilância constante, que classifica, distribui e controla os indivíduos, tanto naqueles espaços extraterritoriais, como também, em certa medida, controla, classifica e disciplina aqueles que estão circunscritos dentro das fronteiras do Esta-

\footnotetext{
${ }^{10}$ O campo de refugiados de Dadaab no nordeste do Quênia é o maior campo de refugiados do mundo, foi aberto em 1991 para abrigar os refugiados que fugiam da guerra civil na Somália, inicialmente construído para albergar um número de 90 mil pessoas. De acordo com os informes da ACNUR (2013) a finais desse ano haviam mais de 463,000 refugiados, incluindo cerca de 10.000 pessoas que conformam a terceira geração, nascida em Dadaab, cujos pais também eram refugiados que nasceram e cresceram nesse campo. Outros campos localizados na África subsaariana, Oriente Médio e na Ásia albergam um considerável número de pessoas refugiadas nesses espaços (ACNUR, 2013).
} 
do-nação. Em suma, trata-se de um agenciamento de um poder que envolve tanto a máquina de guerra ${ }^{11}$ quanto o dispositivo (do) humanitário que operam e agem sobre espaços territoriais e extraterritoriais, que são, em última instância, uma das múltiplas ramificações da sociedade de controle (AGIER, 2003).

Desde essa perspectiva, que aponta a relação entre Estado e formas disciplinares (Foucault, 1999), pode-se afirmar de modo indiscutível o papel central dos Estados-nação nos processos de inclusão e exclusão dos direitos e da cidadania, bem como seu papel principal na fabricação de indivíduos não-cidadãos ${ }^{12}$. Nesse quadro, vemos também, de modo inquestionável, como a linguagem do direito e dos direitos tem pouco alcance para aqueles indivíduos privados de um estatuto de direitos e de cidadania.

Um contraponto importante na reflexão, sobre a relação Estado, território e cidadania, é o conceito de cidadania, descrito em certa medida pelas teorias modernas, que tratam sobre o Estado. Desde Thomas Marshall, Max Weber até Charles Tilly, o conceito de cidadania enquanto categoria analítica tem estatuto central na análise sobre o Estado-nação. Mas, também, desde essas teorias podemos perceber - no caso como analisamos aqui o Estado, em seu papel de inclusão ou exclusão de direitos - que para o Estado, somente são os nacionais aqueles que nascem sob seu território (sob uma

${ }^{11}$ O campo de refugiados de Dadaab no nordeste do Quênia é o maior campo de refugiados do mundo, foi aberto em 1991 para abrigar os refugiados que fugiam da guerra civil na Somália, inicialmente foi construído para albergar um número de 90 mil pessoas. De acordo com os informes da ACNUR (2013) a finais desse ano haviam mais de 463,000 refugiados incluindo cerca de 10.000 pessoas que conformam a terceira geração, nascida em Dadaab, cujos pais também eram refugiados que nasceram e cresceram nesse campo. Outros campos localizados na África subsaariana, Oriente Médio e na Ásia albergam um considerável número de pessoas refugiadas nesses espaços (ACNUR, 2013).

${ }^{12}$ Vale destacar que os processos de inclusão e/ou exclusão dos direitos e da cidadania não só se remetem a um grupo especifico, como no caso dos refugiados, uma vez que tais processos atingem a outros indivíduos e grupos, como tentarei brevemente pontuar mais adiante. 
mesma língua e cultura) ${ }^{13}$, considerados cidadãos possuidores de plenos direitos, podendo assim gozar da "proteção" das instituições nacionais. 0 que tornaria aqueles que nascem dentro de seu território em membros de uma comunidade política. No entanto, considero, contudo, como desde essas abordagens teóricas há uma distância proporcional entre o sujeito cidadão, como parte de um Estado unificado (descrito em certa medida por essas teorias), e o sujeito não-cidadão, que brevemente pretendo explicar a partir de minha pesquisa etnográfica.

\section{Narrativas}

Para começar, proponho considerar, neste texto, alguns relatos dos sujeitos refugiados ${ }^{14}$ (com os quais dialoguei durante o trabalho de campo), que por meio de suas narrativas, apontam alguns elementos importantes sobre a dicotomia sujeito cidadão/ sujeito não-cidadão. Trata-se, então, agora de analisar essas histórias, e verificar o que essas narrativas nos dizem sobre sua condição de refugiados. Assim, os relatos que se seguem, nos podem incidir algumas luzes do que seria esse sujeito não-nacional, e, portanto, desse sujeito não-cidadão, como vermos a seguir.

[...] Eu estou refugiado no Brasil faz cinco anos, embora, o governo tenha atendido minha solicitação e tenha-me concedido o status como refugiado, ainda assim, continuo sendo um estrangeiro, um estranho neste país, pois para mim tem sido mais que evidente que não tenho os mesmos direitos que um nacional, tem sido várias as situações nas que

\footnotetext{
${ }^{13}$ A respeito desse ponto, vale considerar a questão dos povos indígenas que estão dentro das fronteiras do Estado-nação, algo que não é possível aclarar aqui. Entretanto, interessa pontuar as diversidades culturais e linguísticas dessas comunidades, e como eles se representam dentro do Estado.

${ }^{14}$ Os nomes que aparecem neste texto não correspondem ao nome original dos refugiados entrevistados. As falas que aparecem no texto são fragmentos de entrevistas e outras são anotações dessas falas, que escrevi em meu caderno de campo.
} 
tenho-me sentido assim, por exemplo, na área laboral tenho apresentado vários concursos públicos, onde eu sei que posso desenvolver minha profissão, mas em todos eles, sempre tenho sido recusado por não ser nacional, isso é muito frequente no âmbito laboral, porque em outras instâncias tanto institucionais como sociais é mais que evidente que como estrangeiro, e pior ainda como refugiado, não tenho os mesmo direitos que tem um nacional (Carlos, refugiado colombiano, fragmento de entrevista, tradução minha).

\section{0 relato de Alfonso outro refugiado colombiano, ilustra como é estar em situação de refugiado quando coloca que:}

[...] Quando te reconhecem como refugiado, te dão os documentos, tu tens isso na mão, mas por outro lado, ficas no ar, na rua [...] Foi essa a situação não somente minha e de minha família, senão praticamente a que todos os refugiados temos vivido aqui. Você vai a um lado, vai a outro golpeia portas e é um bicho estranho para muitos neste país. Refugiado é sinônimo de fugitivo, isso é muito claro, é um estigma que se carrega [...] Quando uma pessoa solicita refúgio, e lhe concedem o status de refugiado, a essa pessoa lhe dão os documentos, mas ela fica em um limbo, ou seja, a pessoa fica sem saber o que fazer, é dizer cada quem um tem que se salvar como possa [...] Em meu caso particular, eu tentei participar em vários concursos públicos, primeiro tentei entrar em vários setores onde minha educação acadêmica e minha experiência profissional de várias décadas me permitia poder tratar de abrir um caminho, mas que foi totalmente fechado, as portas se fecharam totalmente, e a razão única que me davam é que por ser estrangeiro não podia participar, tentei em outras ocasiões, em algumas áreas como a saúde e foi exatamente a mesma resposta, que o trabalho era só para nacionais ou pessoas nacionalizadas, então se você não quer se nacionalizar, por que não sabes qual é teu futuro, então as portas estão fechadas, acho que falta uma legislação especifica que permita a inserção laboral do pessoal que está refugiado. (Relato de Alfonso, refugiado colombiano, fragmentos de entrevista, tradução minha). 
As narrativas acima, nos permitem perceber como, para o sujeito em situação de diáspora, o estar em um país que o acolhe sob o status de refúgio não garante a ele o pleno exercício de ser cidadão. Ademais, pode-se também perceber, por meio desses relatos, os processos de estigma (GOFFMAN, 1988) pelos que passa o sujeito em situação de refúgio. Vale salientar, que esses processos de estigma que se criam sobre o sujeito em situação de refúgio transbordam o plano das relações sociais e passam a se instituírem também como estigmas institucionais.

Nesse sentido, pode-se dizer que, embora o sujeito em situação de refúgio tenha um status de reconhecimento por parte do Estado receptor, e mesmo um amparo jurídico internacional, (estipulados pelos convênios e tratados internacionais) ${ }^{15}$ ele não conta com os mesmos direitos e garantias, como os que pode gozar um nacional. 0 que (como ouvi frequentemente desses interlocutores) afeta de modo decisivo no processo de integração local, no qual o sujeito em situação de refúgio pretende se inserir. Nesse sentido, cabe destacar o relato de Carmem, refugiada colombiana no Brasil, que aponta sobre processos de estigma, quando coloca que:

[...] Aqui não sabem que é um refugiado, aqui o primeiro que dizem quando se fala de que se é refugiado, o primeiro que pensam é que você é fugitivo de seu país, que a polícia está te procurando, pensam que você é isto ou o outro, pensam que você é um criminoso, como se você fosse um criminoso em seu país. 0 Termo refugiado, aqui no Brasil é muito mal visto, eles não sabem o que é ser refugiado e quando você diz que é refugiado é muito difícil conseguir emprego [...] Na verdade aqui quase não te dão trabalho, os trabalhos que temos conseguido têm sido por indicação de pessoas amigas, e por isso temos conseguido algum tipo de emprego. Se nós vamos com

${ }^{15}$ A respeito dos tratados internacionais que tratam a questão dos refugiados ver a convenção de Genebra de 1951 e suas posteriores modificações. 
um currículo a procurar emprego e ficamos esperado para que nos chamem, isso não funciona. Aqui todo é por indicação. Eu trabalhei na Boticário e tive que explicar a todas minhas colegas o que era um refugiado, por que quando elas ouviram que eu era refugiada, todas elas ficaram assustadas, e muitas delas até falaram mal de meu país, dizendo que Colômbia era um país de drogas, que era um país ruim, falavam sem saber nem conhecer [...] Às vezes, confesso que queria ir embora para outra parte, mas teria que recomeçar tudo de novo, e isso é algo muito difícil. Eu sei de muitos refugiados que estavam aqui e decidiram sair para outras partes, pelas mesmas razões que lhe acabo de falar (fragmentos de entrevista, tradução minha).

Pode-se notar, através dessas narrativas, que mesmo recebendo um amparo jurídico, o sujeito em condição de refugiado sofre algum tipo de discriminação, como preconceito racial, exploração laboral, hostilidade no ambiente de trabalho etc. São alguns dos exemplos que englobam a condição do sujeito refugiado. Todos esses elementos são resumidos em poucas palavras, detentores de estigma como "migrante", "fugitivo", "estrangeiro", "nãonacional"16. Tais conceitos empregados por uma noção local levam, em certa medida, a uma complexa e multifacetada relação entre locais e refugiados, gerando que o processo de integração se torne complexo e gradual. Ou inclusive, em alguns casos, ocasionando que o sujeito em situação de refúgio, no processo de "trânsito" de uma sociedade para outra, não consiga se integrar plenamente na sociedade receptora, como atestam esses relatos.

Simultaneamente, vemos como os imaginários coletivos, que se constroem sobre o sujeito em situação de diáspora, são acompanhados de visiones estereotipadas e negativas, e ao mesmo tempo, de constante recusa sobre as alteridades "não -nacionais". Nesse sentido, ressalta-se como esses imaginários solidificados,

\footnotetext{
${ }^{16}$ Interessa para essa análise ver o trabalho de Vettorassi (2006) no qual discute a relação entre imigrantes nordestinos e locais da cidade Guariba (SP). A autora em seu trabalho destaca como só basta ser de "fora", ou migrante, para ser rejeitado e estigmatizado pelo grupo local, detentor de uma violência simbólica.
} 
que se projetam sobre o sujeito refugiado, se exprimem nas dimensões tanto sociais, como políticas e institucionais. Passando, desse modo, a se constituírem em relações complexas, que passam a ser permeadas por processos de estigma social e violência simbólica (BOURDIEU, 1989) ${ }^{17}$, a qual perpassa o campo das relações (entre refugiados e locais) e passam a se instituírem como estigmas e estereótipos institucionais.

Interessa, nessa reflexão sobre os estereótipos "étnicos", constatar que a existência desses estigmas (como ouvi da maioria dos relatos) cria, muitas vezes, relações tensas entre refugiados e locais. Nesse sentido, cabe aqui para a discussão retomar a análise de Machado, que em seu trabalho Consumo, etnicidade e migração entre imigrantes brasileiros em Portugal aponta sobre os processos identitários e culturais que resultam da relação entre imigrantes brasileiros e portugueses, mostrando como esses processos de interação criam relações, que passam a ser permeadas por "[...] relações profundas (que podemos chamar de classificações sociais, raciais e étnicas) da sociedade receptora sobre os imigrantes" (MACHADO, 2011, p. 10).

Consequente com essa análise, na relação ou interação entre refugiados e locais, também pode-se encontrar uma série de significações e relações (muitas vezes conflituosas) que denotam um certo desencontro das diferenças, as quais, como destaca o mesmo autor, não podem ser vistas como "[...] "dados” ou coisas que apenas existem, mas são processos que envolvem a participação ativa dos sujeitos e daqueles com quem eles se relacionam" (Ibid).

\footnotetext{
${ }^{17}$ De acordo com Bourdieu (1989), a violência simbólica é operada, desde os indivíduos comuns de uma determinada sociedade, bem como pelos mandatários de Estado que possui uma violência simbólica legitima, que inclui a justiça e outras instituições. (Apud VETTORASSI, 2006).
} 
De tal forma, poder-se dizer que essa transição do sujeito em situação de diáspora não se dá sem a ausência de novos conflitos, que vão desde o conflito interior pelo qual passa o indivíduo no processo migratório, até o conflito social no encontro ou confronto com outros novos sujeitos sociais (BARTH, 2000). Ao mesmo tempo, cabe dizer, que essa transição do sujeito em situação de refúgio, de uma sociedade para outra, tem levado, alguns fluxos migratórios, a formar "enclaves étnicos minoritários dentro de Estados-nacionais", que tem levado por sua vez "à pluralização de culturas e de identidades nacionais." 18 (HALL, 1995, p. 66).

Uma vez mais, interessa destacar, sobre os relatos acima, que essas narrativas indicam a dissonância que há entre ter um status de refúgio e ter um estatuto de direito, que como disse-me um refugiado:

[...] não me refiro só direitos políticos, por que eu sei que como refugiado aqui, ou em qualquer outro país não vou ter direitos políticos como os que pode ter um nacional, mas me refiro especificamente aos direitos sociais, que são aqueles que pelo menos me permitem dizer que faço parte de uma sociedade. (Relato de Alberto, fragmento de anotações de meu caderno de campo).

Dessa forma, através dessas narrativas, podemos perceber nitidamente o descompasso que há entre ser reconhecido ou regularizado sob o status de refúgio, e de outro, gozar de um estatuto de direito. Em outras palavras, o que se revela por meio dessas narrativas é a contradição entre o cidadão formal e o não-cidadão social.

\footnotetext{
${ }^{18}$ Contudo, quero destacar que no caso dos refugiados colombianos no Brasil, durante o trabalho de campo não foi possível constatar a formação de enclaves étnicos por parte desse grupo, como acontece com outros grupos de refugiados ou migrantes, mas, bem, o que constatamos durante a pesquisa de campo é que se trata de um grupo atomizado, com poucas relações e vínculos entre si.
} 
Nesse sentido, pode-se afirmar que a condição do sujeito não-cidadão, do sujeito sem direitos na sociedade contemporânea, não só se remete a esse (ou a um) determinado grupo especifico. $\mathrm{Na}$ medida em que também podemos constatar que na atual sociedade globalizada, estratificada e estruturalmente hierarquizada, outros grupos pertencentes a estratos sociais, economicamente desfavorecidos, nascidos e circunscritos dentro das fronteiras dos Estados-Nação, não são provedores, ou são privados de um estatuto de direito e cidadania (embora eles o tenham formal e legalmente), passando, desta forma, a se tornarem, portanto, em sujeitos não-cidadãos (FELTRAN, 2008).

Essa análise, por outro lado, nos permite refletir sobre os processos de inclusão e exclusão dos direitos e cidadania, bem como através dela, podemos repensar, como na sociedade contemporânea tanto os sujeitos não-cidadãos "nacionais", como os refugiados, apátridas migrantes etc., parecem situar-se fora do mundo, que como bem destaca Birman (2009), é aquele que é socialmente organizado e condicionado no interior dos Estados-nação. Ou, em outras palavras, esses sujeitos banidos de um estatuto de direitos e de cidadania passariam a se tornar, na atual ordem global contemporânea, em simples corpos situados no "mundo do além" (AGIER, 2012).

Outro aspecto a mencionar é que, embora, o estatuto de cidadania e do direito sejam conceitos e categorias frequentemente empregadas nas ciências sociais (que com recorrência toma a definição destes conceitos da filosofia aristotélica, ${ }^{19} \mathrm{e} /$ ou de concepções modernas, como a tríade de T. Marshall ${ }^{20}$ )

\footnotetext{
${ }^{19}$ De acordo com Ranciere (1996), o conceito aristotélico define: "um cidadão em geral é aquele que participa do ato de governar e do de ser governado". (RANCIERE, 1996).

${ }^{20}$ De acordo com Marshall (1967, p. 63) o direito de cidadania se divide em três partes: direitos civis, políticos e sociais. 0 elemento civil é composto por direitos necessários à liberdade individual - liberdade de ir e vir, liberdade de impressa, pensamento e fé, e o direito à justiça. 0 elemento político, diz respeito ao direito ao exercício de participar no poder político. 0 elemento social, se refere a tudo o que vai desde o direito a um mínimo de bem-estar econômico e social.
} 
enquanto categorias analíticas, na compreensão e funcionamento do Estado-nação. Essas noções, no entanto, parecem camuflar uma certa armadilha conceitual, na medida em que parecem ser quase um decalque imutável do conceito de cidadania da arcaica polis grega, empacotadas e prontas de forma a ser empregadas de uma forma mais sofisticada e mistificada pelas modernas sociedades democráticas ${ }^{21}$. Como descreve Feltran (2008) “(...) supõe-se que o direito é a medida universal e normativa de acesso à sociedade e à política, e a existência de massas alheias ao direito, que se avulta, seria uma espécie de desvio, imperfeição ou incompletude da norma democrática." (FELTRAN, 2008. P. 17).

Simultaneamente, essas noções derivadas de uma linguagem política e institucional, no entanto, revelam, em certa medida, a contradição entre um cidadão formal e um não-cidadão social, ao se verificar como na sociedade hierárquica se cria uma fronteira nítida entre os cidadãos, potenciais portadores de direitos, e aqueles a serem privados deles (FELTRAN 2008). Por outro lado, essas noções empregadas tanto no campo da política e das instituições como nos diversos aspectos da vida social, levam à necessidade de analisar e problematizar como essas categorias operam e se exprimem na sociedade contemporânea.

Nesse sentido, o estudo dessas categorias pode ser melhor compreendido desde uma análise etimológica que procure não só o sentido originário das palavras, mas sim suas propriedades intrínsecas (FOUCAULT, 2000, p. 51). Poderíamos desarmar (destrinchar) essas armadilhas conceituais, desvendando assim como antigos valores e representações se mantêm vivos sob novas roupagens conceituais.

${ }^{21}$ Acredito que nesse sentido é possível afirmar que como o cidadão da antiga polis grega, também na sociedade contemporânea quem tiver mais poder de posse, embora não formal, nem legalmente, terá mais direitos e benefícios, tornando-se, portanto em um pleno cidadão. 
Em face desses elementos apontados acima, cabe aqui retomar para a discussão a análise de Leirner (2012) que em seu trabalho histórico-etimológico Estado, como fazenda de domesticação destaca a importância de uma etimologia, que como bem coloca, citando Herzfeld (1997): "não é das palavras, mas dos agenciamentos que se faz com elas". Apontando, ademais, "[...] que, o surgimento de um modo de pensar na Grécia arcaica produziu um esquema cosmológico tão poderoso que as instituições ocidentais ou estão presas por uma certa miopia conceitual, ou bem desejam acreditar que são universais e, por isso mesmo inexoráveis ou, possivelmente, ambos." (LEIRNER, 2012, p. 58).

Essa análise, por outro lado, também, nos leva a refletir sobre a necessidade de problematizar e (por que não) desconstruir certos conceitos. Ou, então, substituir certos conceitos problemáticos por outros tão ou mais comprometidos que aqueles que se deseja abandonar (GOLDMAN, 1996). Como foi mencionado acima, se conceitos como direito e cidadania são considerados pelo pensamento moderno ocidental como noções universais e inexoráveis, note-se, em todo caso, que essas noções são também intrinsecamente ambíguas e ambivalentes na forma como elas operam social, política e institucionalmente na sociedade contemporânea. Em suma, desde uma reflexão etimológica de ditos conceitos poderíamos repensar e descodificar (desde o ponto de vista histórico, epistemológico e político) as dinâmicas temporais em que esses conceitos são utilizados.

Contudo, a intenção deste texto, não é entrar em explicações etimológicas ${ }^{22}$ desses conceitos, mas sim, apontar limitadamente sobre sua perenidade (em sua contradição imanente) presente desde a Grécia antiga, bem como seu posterior acoplamento à sociedade moderna. Ou, em outras palavras, tentamos tratar

${ }^{22}$ Foucault (2000, p. 51) ressalta que "a etimologia não é uma ciência que busca o sentido originário das palavras, mas, sim as propriedades intrínsecas das palavras”. (FOUCAULT, 2000). 
aqui apenas de ressaltar a ambiguidade que engloba esses conceitos, como pedra angular da sociedade moderna. Como na antiguidade, essas noções podem exprimir os mesmos códigos de hierarquização social e política, reforçando e aperfeiçoando, tacitamente, estruturas de desigualdade social.

Como foi rapidamente mencionado acima, não se trata aqui de desconstruir esses conceitos, pois essa é uma questão intrincada, que não é o objetivo neste trabalho. Pelo momento, o que procurei demonstrar por meio de um breve embasamento teórico e de rápidas narrativas tomadas de minha pesquisa de campo foi, através da noção de condição do sujeito refugiado, apontar como a dicotomia sujeito/cidadão, e sujeito/não-cidadão, se faz presente na vida do sujeito em condição de diáspora. Vimos, através dessas narrativas, como a linguagem do direito e dos direitos tem pouco alcance para o sujeito em situação de refúgio. Também apontei como essa dicotomia se desdobra para outros indivíduos e grupos nascidos e circunscritos dentro das fronteiras do Estado-Nação, que embora mesmo sendo reconhecidos formal e legalmente como cidadãos, na vida social são privados de um estatuto de direito e cidadania.

Nosso seguinte objetivo agora é tentar repensar a partir dessas narrativas nativas as causas que produzem o êxodo forçado ou, enfim, discutir a ligação (relação) entre a migração forçada e as dinâmicas de guerra e espólio imbricadas ao processo de acumulação de capitais, em um contexto de globalização ${ }^{23}$. Tema que pretendo discutir a seguir.

${ }^{23} \mathrm{O}$ complexo fenômeno da globalização levou a uma "quebra das fronteiras" que gerou uma expansão do fluxo de capitais, o qual foi possível através das grandes transações financeiras e a expansão dos mercados. De acordo com Cantor (2014) a noção de globalização também foi vendida como uma suposta nova época que beneficiaria a todos os países por igual e, em certa medida, é uma noção que se emprega de forma abusiva, com a suposta ideia de que tornou o mundo interligado em uma aldeia global. 


\section{Êxodo forçado e dinâmicas de guerra}

Como descrevi no início do texto, migrações forçadas, ou induzidas por processos de guerra ou violência, não se constituem em um fenômeno recente da história. Ao mesmo tempo, indiquei que essas se intensificaram na sociedade contemporânea, na medida em que se desenvolvem os conflitos e ações bélicas nas regiões consideradas às "margens do mundo". Também mencionei que esses fluxos migratórios têm sido analisados desde diferentes áreas disciplinares, que têm contribuindo em aspetos importantes sobre esses deslocamentos. Contudo, cabe salientar que esses movimentos migratórios quando analisados têm sido principalmente estudados focando no estudo das populações deslocadas, nas estimativas numéricas, bem como na identificação de seus locais de destino e, em outros casos, seus movimentos de retorno, uma vez terminados os conflitos (PETRUS, 2000).

Nesse sentido, proponho nesta parte do texto analisar e discutir um outro aspecto desse processo migratório pouco abordado pelos estudos que tratam sobre o tema. Em outras palavras, trata-se, aqui, de uma tentativa de explorar as causas que produzem ditos deslocamentos a partir da relação entre êxodo forçado e dinâmicas de guerra, pensadas aqui, como processos imbricados e, ao mesmo tempo, necessárias à acumulação de capitais.

Quero destacar que essas relações (entre dinâmicas de guerra, êxodo forçado e acumulação de capitais) que tento analisar, em certa medida, são um dado etnográfico que resulta das narrativas nativas que ouvi durante o trabalho de campo. Essas informações derivadas de uma experiência nativa são desdobradas aqui em duas reflexões que ao mesmo tempo prospectam essas relações: a primeira diz respeito sobre a migração forçada como possível processo "essencial" ao processo de reordenamento 
global $^{24}$ (isto falando desde um sentido mais geopolítico). E uma outra que diz respeito sobre a relação entre o desenvolvimento do aparelho militar, ou máquina de guerra no sentido deleuziano, e o processo migratório contemporâneo ${ }^{25}$.

Para levar adiante tanto a relação entre dinâmicas de guerra e êxodo forçado, bem como as reflexões que desta se derivam, tomo como recorte metodológico um grupo "étnico" especifico (refugiados colombianos no Brasil). E uma situação de conflito em um contexto local (Colômbia) como unidade de análise para pensar esses processos e suas relações. Nesse sentido, quero retratar um pouco o conflito armado na Colômbia, o qual tomo como espaço especifico de análise dessas dinâmicas, e uma possível extrapolação desse recorte na medida em que parto dele para tentar pensar essa relação em um contexto mais abrangente.

Na Colômbia, o conflito armado e suas dinâmicas de guerra e violência têm levado a um êxodo forçado, massivo e continuo de populações com características heterogêneas diferentes. Essas dinâmicas de violência têm sido consideradas como processos inerentes à história e à formação social e política desse país (ÀLAPE, 1985). Para Medina (1991), os processos de violência e os deslocamentos que este produz fazem parte de um processo histórico que o autor denomina de violência estrutural da sociedade colombiana (MEDINA, 1991, p. 101). Característica que permanecerá no tempo e no espaço dentro das relações de formação da sociedade colombiana.

\footnotetext{
${ }^{24}$ Nos últimos anos com a consolidação dos processos de globalização ou mundialização houve uma reconfiguração no campo da economia da política no cenário internacional, mas, sobretudo, houve também uma reconfiguração do mapa geopolítico e geoestratégico no reposicionamento do controle dos territórios, através de conflitos tanto entre Estados como conflitos internos.

${ }^{25}$ No entanto, considero que essas são reflexões cujos desdobramentos podem ser encontrados entre aqueles que lidam com essas situações: os refugiados e desplazados.
} 
Compreender esses processos é uma questão complexa na medida em que nesses processos envolvem uma multiplicidade de fatores, tanto histórica como sociais. Contudo, essas dinâmicas de violência se revelam de forma nítida, na medida em que se desenvolve o conflito entre o Estado e os grupos irregulares, tornando-o um dos conflitos mais antigos e conflitantes que tem levado a um dos maiores deslocamentos do hemisfério ocidental (HOBSBAWM, 1995).

Esses processos de deslocamento têm sido monitorados por organismos, como a ACNUR, HUMAM RIGHTS e CODHES, os quais apontam em mais de 5 milhões, o número de deslocados internos, nos últimos trinta anos, como consequência dessas dinâmicas de guerra que se desenvolvem em grande parte do território. No entanto, o número de refugiados colombianos disseminados em outros cantos do mundo, supera os 390.000 (ACNUR, 2012) ${ }^{26}$.

A diáspora colombiana, como bem assinalou Mejía (2010), coloca a Colômbia como um dos países que mais expulsa seus próprios nacionais, dentro e fora de seu território, por motivos de guerra e violência, seguida por países como Iraque, Afeganistão e República Democrática do Congo (CODHES, 20010), constituindo-se, deste modo, em um êxodo forçado, contínuo, heterogêneo social e regionalmente.

No entanto, cabe dizer, inclusive a partir dos relatos que coletei, que essas dinâmicas de guerra e deslocamentos forçados afetam principalmente às comunidades tradicionais (camponeses, indígenas e afrodescendentes) mais afastados dos centros urbanos, na medida em que a intensificação do conflito, pelos senhores de um ethus guerreiro, se desenvolve principalmente em teatros

${ }^{26}$ Tendências globais ACNUR 2012. Disponível in: http://www.acnur.org/t3/fileadmin/ scripts/doc.php?file=t3/fileadmin/Documentos/Publicaciones $/ 2013 / 9180 \quad$ acesso 21/04/2014. 
de operações, como são denominados pelos militares as regiões em disputa. Mas, para o objetivo deste trabalho, considero pertinente nomear esses locais de zonas às margens do estado ${ }^{27}$ (DAS; P00LI, 2004), uma vez que estas ditas zonas também são supostos necessários para o Estado, bem como para os interesses do mercado internacional.

Essas regiões às quais me refiro são consideradas, inclusive por alguns de meus interlocutores com os quais dialoguei, estratégicas pelo grande potencial de recursos naturais que nelas há. Em outras palavras, creio que se trata de territórios em disputa, que por seu valor geoestratégico e geopolítico se tornam em zonas essenciais para o interesse e desenvolvimento do Estado, como também se tornam fundamentais para a acumulação de capitais, tanto nacionais, quanto internacionais.

Cabe aqui para acrescentar a essa discussão, destacar, o relato de Mario, solicitante de refúgio, com quem dialoguei durante meu trabalho de campo em Manaus no ano de 2012, que, de algum modo, aponta para os processos de espólio associado diretamente às dinâmicas de guerra, ao assinalar que:

[...] Minha origem é camponesa, nasci e me criei no campo, o conflito esteve sempre presente em nossa região. Eu não entendo muito de política, mas o que sei, é que nossa desgraça começou quando se incrementaram os operativos militares na região. Primeiro chegaram os paramilitares, desaparecendo e assinando às pessoas, acusavam-nos de sermos auxiliadores da guerrilha. Muitos fomos forçados a abandonar nossas terras. Muitos camponeses da região foram obrigados a assinar documentos em notarias como se estiveram vendendo suas terras. A maioria dessas terras passaram a mãos de latifundiários e empresas multinacio-

${ }^{27}$ Como bem destaca (DAS; POOLI, 2004) "uma antropologia das margens oferece uma perspectiva única para compreender ao estado, não porque capture práticas exóticas, senão porque sugere que ditas margens são supostos necessários dos estados, da mesma forma que a exceção é a regra". 
nais. A região passou a ser invadida pela monocultura, principalmente pelo monocultivo da palma, que é de onde estão extraindo agora combustível e etanol. [...] A violência nas regiões rurais não é de agora, há décadas o camponês está sendo deslocado e massacrado (fragmentos de entrevista).

Note-se como o fenômeno do deslocamento (interno e externo) na Colômbia merece destaque na análise sobre o fenômeno migratório internacional, uma vez que, a inter-relação entre as múltiplas causas que originam o conflito na Colômbia levam a um fenômeno de deslocamentos massivos com características específicas dentro do contexto mundial. Em particular, as formas de deslocamento, as estimativas numéricas, as zonas de origem e de destino dos deslocados, assim como o número de atores estatais e não estatais envolvidos. De qualquer forma, todos esses elementos são fatores que indicam as condições especiais do fenômeno da migração forçada nesse país.

Por outro lado, há que salientar que, nesse processo, aparece um número importante de discrepâncias nas zonas afetadas pela violência, que levam aos deslocamentos massivos: de um lado, entre os camponeses e suas organizações representativas, e de outro, o poder econômico e coercitivo dos grandes latifundiários e do Estado, atrelados por sua vez aos interesses do capital internacional.

Como destaca Roldán (2000) "Claramente detrás do conflito armado no que participam a Força pública, os paramilitares ${ }^{28}$ e os grupos guerrilheiros existe um conflito muito sério que protagonizam os camponeses e os grandes proprietários da terra no país". Roldán (ibid) destaca ademais que ambos conflitos convivem especialmente em zonas nas quais há fortes interesses

${ }^{28}$ Destaco, que embora esteja tratando aqui os grupos paramilitares ou paraestatais como grupos irregulares, estes funcionam como exércitos irregulares contrainsurgentes, em outras palavras esses grupos são uma extensão do Estado por outros meios. Como bem destaca (DAS E POOLE, 2008) "as forças paramilitares colombianas atuam tanto como uma extensão do exército como condutos por onde fluem o tráfico de armas e de drogas". 
comerciais, como as zonas pecuárias, as áreas de exploração petroleira e as regiões de grandes jazidas de mineração. 0 que faz que essas zonas se tornem, por sua vez, no epicentro do conflito armado. E, ao mesmo tempo, se tornem em zonas estratégicas de grande interesse para o capital internacional.

Nesse reposicionamento, o controle dos territórios e das organizações tanto camponesas como sociais é estratégico tanto para o Estado colombiano, como para os grupos armados que confrontam a este. Portanto, esses territórios tem um especial significado geoestratégico para ambas partes em confronto. Mas, principalmente, o domínio e controle desses territórios têm maior significado para o Estado atrelado aos interesses do grande capital internacional.

Em todo caso, todos esses atores geradores de violência buscam ganhar domínio político e militar nas zonas com alta densidade demográfica. Esses elementos indicam, por sua vez, que a dinâmica em que se desenvolve o conflito se cruza e articula ao mesmo tempo três processos de luta diferentes: a social, a política e a militar (GARCIA, 1997, p. 140).

Nesse sentido, a imbricação desses três tipos de conflito leva a uma intensificação do conflito na Colômbia com características particulares de outros conflitos (sejam entre Estados, que coloca em confronto exércitos regulares claramente num espaço de operações militares, dispostos para tal finalidade, ou seja, conflitos de caráter interno ou cível onde predominam técnicas e modelos irregulares de combate). A forma que assume esse conflito é o da conquista dos territórios seja mediante a coerção física, ou seja, através da "conversão", ou da expulsão das populações que habitam nessas regiões.

[...] Eu sou da comunidade Baniwa do alto Vaupes, [...] muitos membros da comunidade fomos deslocados pelo conflito, eu sai deslocada de minha comunidade no ano de 2004, 
sai fugindo de lá por que assinaram a meu esposo, a meus dois filhos maiores, ao marido de minha filha, todos eles foram mortos no mesmo dia [...] estou aqui (Manaus) desde começo de 2011, com meus outros quatro filhos que ficaram [...] quase todas as pessoas da comunidade foram deslocadas e outras foram assassinadas como aconteceu com minha família [...] os enfrentamentos entre exército e guerrilha tem deslocado a muitas comunidades dessa região (Relato de Maria, Indígena Baniwa).

Em face desses elementos mencionados, destaca-se que as especificidades em que se desenvolvem as dinâmicas de guerra, no marco do conflito na Colômbia, levam à ideia de que estas dinâmicas conduzem a um duplo processo de força centrípeta e centrifuga em continua expulsão de populações (principalmente tradicionais: indígenas, camponesas, afrodescendentes e extrativistas, situadas às "margens" ou periferias do Estado). Esse duplo processo acontece, em certa medida no sentido de Clastres, não como evitação do Estado, ou do Um, enquanto entidade totalizante, como no caso das comunidades ameríndias por ele estudadas ${ }^{29}$ que conjuram a formação do Estado, através da guerra $^{30}$. Tomando um pouco dessa ideia, e em certa forma, fazendo uma inversão dela, em minha opinião, creio que as dinâmicas de guerra no marco em que se desenvolve o conflito na Colômbia levam a esse duplo processo (centrípeto e centrífugo) a funcionar como vetor que conduz não à evitação, senão à formação e consolidação do Estado-nação colombiano, cuja ferramenta política propícia para sua consolidação é a própria guerra como extensão do Estado por outros meios, imbricada diretamente ao processo de acumulação de capitais.

\footnotetext{
${ }^{29}$ Pierre Clastres (1974), "por exemplo, reivindicava que a racionalidade e as formas de vida próprias de nossos objetos etnográficos não modernos podiam ser entendidas de uma melhor maneira se os considera como uma expressão de um desejo coletivo de evitar a emergência do estado" (DAS; POOLI, 2008).

${ }^{30}$ Clastres observou que nas sociedades ditas primitivas a guerra é o mecanismo mais seguro contra a formação do Estado, já que esta mantém a dispersão e segmentaridade dos grupos (DELEUZE; GUATTARI, 2008).
} 
Essas dinâmicas de guerra como extensão do Estado, por outros meios em suas margens, em certa medida, também são encontradas sob outras formas e moldes, disciplinadores e regularizadores, sobre outras regiões, onde se desenvolvem conflitos internos ou de guerra civil. Muitos deles, exacerbados pelos Estados Capitalistas centrais. Nesse sentido, não deixa de ser interessante assinalar que os interesses econômicos e geopolíticos dos países capitalistas centrais têm tido como foco geoestratégico de interesse principal os países periféricos, ou de um capitalismo tardio, como o é o caso da Colômbia, cuja economia se insere na órbita de um capitalismo periférico com uma economia primária de tipo exportador, que, por sua vez, está imbricada com o despojo territorial de camponeses, indígenas e comunidades afrodescendentes que levam essas comunidades a deslocamentos contínuos.

Ao mesmo tempo, interessa sobre essa reflexão destacar que os Estados capitalistas centrais utilizam certas dinâmicas que giram em torno do econômico, do político e, sobretudo, do militar, para promover e criar cenários de conflitos em regiões que, como mencionei acima, possuem um alto potencial de recursos, que podem ser, ou na maioria dos casos são, expropriados para logo serem exploradas para a concentração infinita de capitais. Como destaca Harvey (2004, p. 100), essa situação seria o resultado de uma incapacidade do sistema econômico hegemônico de não conseguir mais acumular, através de uma reprodução ampliada - característica do capitalismo até mediados do século XX -, "que tem sido acompanhada por crescentes intentos de acumular mediante a desapropriação".

De tal forma, pode-se arriscar a dizer que tanto na Colômbia como em outras regiões em conflito, sejam convencionais ou irregulares, se impulsionam processos de "recolonização" que se inscrevem na órbita do que Harvey (2004) denomina de "acumulação por desapropriação", característica do que ele considera como a face de "Novo imperialismo". 
Nessa mesma linha de análise, Cantor (2014) considera que entre os mecanismos dessa acumulação por desapropriação se encontra a mercantilização de todos os bens comuns, entre eles, a água, a biodiversidade natural, os bosques e os saberes ancestrais dos povos tradicionais, o que estaria imbricado ao renascer da extração mineira e o ressurgir das economias primárias de tipo exportador, cujas implicações se exprimem na desindustrialização, na desapropriação territorial dos povos indígenas, camponeses e afrodescendentes situados nas "margens do Estado", bem como a militarização da vida cotidiana. Em suma, essas dinâmicas de guerra imbricadas à "acumulação por desapropriação" asseguram o fluxo de matérias primas e energia para os Estados capitalistas centrais, cuja finalidade é manter a acumulação de capital, que possibilita e perpetua seus níveis de produção e consumo.

\section{Considerações finais}

Neste texto discuti mais detalhadamente alguns elementos da migração forçada, a partir das experiências e trajetos de vida dos sujeitos em situação de refúgio. Essas experiências nativas revelaram uma série de elementos e fatores que se fazem presentes na vida do sujeito em situação de diáspora, principalmente, aquelas que se referem no âmbito do Direito e os diretos.

Como vimos, essas narrativas nativas indicavam, em primeira medida, o descompasso entre ter um status de refugiado e, de outro, ter um estatuto de cidadão. Por outro lado, essas experiências revelavam em certa medida uma certa dicotomia entre um sujeito cidadão e sujeito não-cidadão. Havia assim, uma ambiguidade ou ambivalência do conceito de cidadania que estava presente no cotidiano de nossos interlocutores. Apontamos, desta forma, como o estatuto do direito e da cidadania tem pouco alcance para o sujeito em situação de refúgio. Como foi detalhado, através dos relatos era mais que evidente que embo- 
ra tivessem um status de reconhecimento como refugiados, na prática social e política não possuíam os mesmos direitos como qualquer outro cidadão.

Essas experiências nativas também nos levaram a refletir sobre os processos geopolíticos e biopolíticos, cujos processos econômicos, políticos, sociais e militares, como foi indicado, não cessam de fabricar indivíduos não-cidadãos. Interessa sobre essa reflexão, destacar que também através dessas experiências verificamos o papel central do Estado- Nação no que se refere aos processos de inclusão e exclusão de direitos e cidadania.

Sobre esse ponto tomei como exemplo o trabalho de Agier (2003; 2008) sobre os campos de refugiados para indicar como nesses espaços extraterritoriais, ou também denominados por aquilo que chamei de dispositivo (do) humanitário, se moldam às práticas políticas de controle, regulação e disciplinamento que constituem aquilo que denominamos de Estado.

Em suma, o exemplo explorado indicou que esse mecanismo se revela em certa medida como uma nova forma biopolítica de controle, gerenciamento e disciplinamento do poder soberano, o qual o definimos aqui nos termos de Foucault (2010) do poder sobre a vida e a morte. Finalmente, descrevemos os processos de estigma social (GOFFMAN, 1988) e violência simbólica (BOURDIEU, 1989) pelos que passa o indivíduo em situação de refúgio. Através de suas experiências percebemos como esses processos de estigma e violência simbólica perpassam o campo das relações sociais entre refugiados e locais e passam a operar também de forma tênue tanto em discursos como em práticas institucionais. 


\section{Ref erências}

AGIER, M. Refugiados Diante da Nova Ordem Mundial. In: Tempo Social, 2006, vol.18, 2006.

AGIER, M. Uma exceção redobrada. Espaços, tempo e atores do governo humanitário. Tradução de Silvia Naidin. In: Desigualdade \& Diversidade. Revista de Ciências Sociais da PUC Rio, edição № 11, 2012.

ALAPE, A. La paz, la violencia: testigos de excepción. Bogotá: Editoria, 1985.

ANDRADE, J. H. F. A proteção internacional dos refugiados no limiar do século XXI. Travessia - revista do migrante. São Paulo. 1996, 1996.

ANDRADE, J. H. F. A lei brasileira de proteção aos refugiados. Correiro Brasiliense. Brasília. Caderno Direito \& Justiça, 1997.

ARENDT, H. O Declínio do Estado-Nação e o fim dos Direitos do Homem. In: As Origens do Totalitarismo. São Paulo: Companhia das Letras., 1989.

BARTH, F. O Guru, o Iniciador e Outras Variações Antropológicas. Rio de Janeiro: Contra Capa Livraria, 2000, 2000.

BIRMAN, P. Resenha: AGIER, Michel. Gérer les indésirables: des camps de réfugiés au gouvernement humanitaire. Horizontes. Antropológicos. Vol 15 no. 32 Porto Alegre July/Dez. 2009., 2009.

BOURDIEU, P. 0 poder simbólico. Lisboa: Difel, 1989.

CANTOR, R; NOVOA, F. Colombia y el imperialismo contemporaneo. Editoira Ocean Sur, 2014. Consultoría para los Derechos Humanos y el Desplazamiento. http://www.codhes.org/index.php?option=com_contentHYPERLINK "http://www.codhes.org/index.php?option=com_content\&task=view\&id=9 74"\&HYPERLINK "http://www.codhes.org/index.php?option=com_content \&task=view\&id=974"task=viewHYPERLINK "http://www.codhes.org/index. php?option=com_content\&task=view\&id=974"\&HYPERLINK "http://www. codhes.org/index.php?option=com_content\&task=view\&id=974"id=974

DAS, V.; POOLE, D. EL Estado y sus Margenes. Etnografias comparadas. Cuadernos de antropologia social № 27. 2008.

DELEUZE; G. Mil platôs: Capitalismo e Esquizofrenia. Vol. 5. Editora 34, 2008.

FELTRAN, G. A fronteira do Direito: Política e violência na periferia de São Paulo. In: DAGNINO: TATAGIBA, L.. (ORG). Democracia e sociedade civil e participação. Chapecó; Editora Argos, 2007, v. P537-566. 
FOUCAULT, M. As palavras e as coisas. Uma arqueologia das ciências humana. São Paulo. Martins Fontes, 2000.

FOUCAULT, M. Em Defesa da Sociedade. São Paulo: Martins Fonte, 2010.

GARCIA, C. A. Urabá: Políticas de paz y dinâmicas de Guerra. Estudios Políticos No. 10. Medellín, Enero - Junio 1997.

GOFFMAN, E. Estigma: Notas sobre a manipulação da identidade deteriorada. 4⿳ạ edição. Rio de Janeiro:LTC, 1988.

GOLDMAN, M. Uma categoria do pensamento antropológico: a noção de pessoa. Revista de Antropologia, 39(1):83-109. 1996.

HARVEY, D. El "nuevo” imperialismo: acomulación por desposesión. En publicacion: Socialist Register 2004. CLACSO, Consejo Latinoamericano de Ciencias Sociales, Ciudad Autonoma de Buenos Aires, Argentina: Enero. 2005 9871183-10-0.

HOBSBAWN, E. Era dos Extremos: o breve século XXI (1914-1921). 2 ed. Tradução Marcos Santa Rita. São Paulo: Companhia das Letras, 1995.

LEIRNER, P. O Estado como fazenda de domesticação. R@U. Revista de Antropologia da UFSCar, v.4, n.2, jul.-dez., p.38-70, 2012.

MACEDO, P. E. B. A ingerência humanitária e a guerra justa. Disponível IN. Revista de direito da Uningranrio 1(1), 2008.

MACHADO, I.J.R. Consumo, etnicidade e migrações entre imigrantes brasileiros em Portugal. Revista temas de Antropologia y Migração № 2., 2011.

MARSHALL, T. H. Cidadania e classe social. Rio de Janeiro: Zahar, 1967 p. 57114.

MEDINA, C. Autodefensas, paramilitares y narcotráfico en Colombia: origen, desarrollo y consolidación: el caso "Puerto Boyacá”. 1990 Bogotá: Documentos periodísticos, 1990.

MEJÍA, E R. Desterritorialização e Resistências viajantes forçados colombianos em São Paulo e Barcelona. Campinas: 2010. Tese de doctorado, 2010.

MENEGHEL, S. N. 0 Homem Elefante: reflexões sobre saúde doença e anormalidade. Interface, comunicação saúde educação. v.12, n.25, p.427-32, abr./ jun. 2008 .

MOLANO, A. Desterrados. Crônicas do desarraigo, Bogotá: Ancora Ed., 2001.

PETRUS, R. Jovens migrantes angolanos no rio de janeiro: Imagens, relatos e diálogos. Travessia revista do migrante. Publicação do CEM- Ano XIII. № 37. 2000. 
RENCIÈRE, J. A crise da razão: 0 dissenso. Companhia das letras, 1996.

ROLDAN, G. Z. Los desplazados internos por la volencia: um problema fundamental en Colombia. Disponível in: http://www.oas.org/juridico/spanish/zafra.html Acesso realizado 14/04/2014, Sd.

TILLY, C. Coerção, capital e estados europeus. 990-1992. Edusp, 1996.

VETTORASSI, A. Espaços divididos e disputados: relações sociais entre nativos e os "de fora" em Guariba - SP. Travessia revista do migrante. Publicação do CEM. Número 54, janeiro-Abril/2006.

Recepção dos artigos: 30/06/2015

Data de aprovação 30/07/2015 